\title{
Cerebellar Hemorrhage due to a Direct Carotid-Cavernous Fistula after Surgery for Maxillary Cancer
}

\author{
Yoshinobu Kamio, M.D., ${ }^{1}$ Hisaya Hiramatsu, M.D., ${ }^{1}$ Mika Kamiya, M.D., ${ }^{2}$ Shuhei Yamashita, M.D., ${ }^{2}$ Hiroki Namba, M.D., Ph.D. \\ Department of Neurosurgery, Department of Radiology, ${ }^{2}$ Hamamatsu University School of Medicine, Hamamatsu, Japan
}

Infratentorial cerebral hemorrhage due to a direct carotid-cavernous fistula (CCF) is very rare. To our knowledge, only four such cases have been reported. Cerebellar hemorrhage due to a direct CCF has not been reported. We describe a 63-year-old female who presented with reduced consciousness 3 days after undergoing a maxillectomy for maxillary cancer. Computed tomography showed a cerebellar hemorrhage. Magnetic resonance angiography showed a left-sided direct CCF draining into the left petrosal and cerebellar veins through the left superior petrosal sinus (SPS). Her previous surgery had sacrificed the pterygoid plexus and facial vein. Increased blood flow and reduced drainage could have led to increased venous pressure in infratentorial veins, including the petrosal and cerebellar veins. The cavernous sinus has several drainage routes, but the SPS is one of the most important routes for infratentorial venous drainage. Stenosis or absence of the posterior segment of the SPS can also result in increased pressure in the cerebellar and pontine veins. We emphasize that a direct CCF with cortical venous reflux should be precisely evaluated to determine the hemodynamic status and venous drainage from the cavernous sinus.

Key Words : Direct CCF · Superior petrosal sinus · Cerebellar hemorrhage.

\section{INTRODUCTION}

A direct carotid-cavernous fistula (CCF) can result from trauma, rupture of a cavernous carotid aneurysm, or a tear in the wall of a cavernous internal carotid artery (ICA) weakened by collagen vascular disease. The clinical symptoms of a direct CCF are related to its venous drainage pattern. Intracerebral hemorrhage from a direct CCF is very rare, occurring in only $0.9 \%$ of direct CCF cases according to Sattler". The anatomy of the superior petrosal sinus (SPS) and the infratentorial cortical venous reflux influence brainstem con- gestion and infratentorial cerebral hemorrhage. We report a case of cerebellar hemorrhage due to a direct CCF after total maxillectomy for maxillary cancer.

\section{CASE REPORT}

A 63-year-old female with left maxillary cancer was initially treated with arterial injection chemotherapy, which reduced the tumor size. Six months later, she underwent surgical treatment for recurrent cancer. The surgery included left

- Received: June 1, 2015 •Revised: September 9, 2015 •Accepted: September 25, 2015

- Address for reprints : Yoshinobu Kamio, M.D.

Department Neurosurgery, Hamamatsu University School of Medicine, Handayama 1-20-1 Higashi-ku, Hamamatsu, Japan

Tel : +81-53-435-2283, Fax : +81-53-435-2282, E-mail : kamio880@hotmail.com

This is an Open Access article distributed under the terms of the Creative Commons Attribution Non-Commercial License (http://creativecommons.org/licenses/by-nc/4.0) which permits unrestricted non-commercial use, distribution, and reproduction in any medium, provided the original work is properly cited. 
maxillectomy and resection of the coronoid process of the mandible, inferior wall of the orbit, and part of the pterygoid process (Fig. 1A). The left facial vein and left pterygoid plexus were sacrificed. Three days after surgery, her level of consciousness rapidly decreased. Computed tomography and magnetic resonance imaging showed hemorrhage in the left cerebellar hemisphere with surrounding edema (Fig. 1B, C). Neurological examination revealed bilateral orbital bruits, left-sided chemosis and conjunctival hyperemia, and nearcomplete loss of vision in the left eye. She had left-sided cerebellar ataxia but no apparent muscle weakness. Left ICA angiography showed a left direct CCF with large fistulas. The
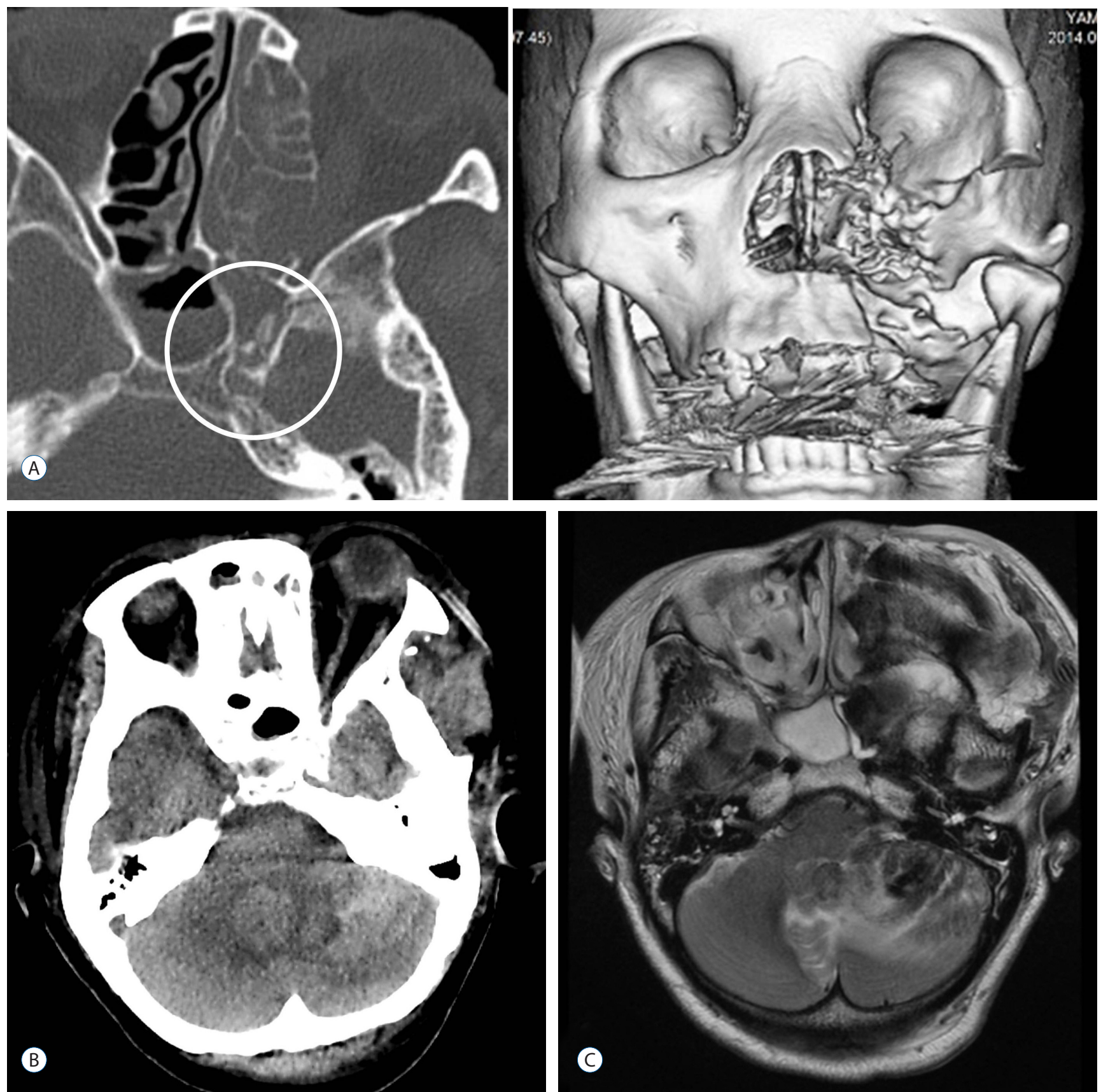

Fig. 1. $C T$ bone image and $3 D$ reconstruction $(A)$ showing absence of the resected pterygoid process, and a bony spicule adjacent to the foramen lacerum (open circle). CT (B) and T2-weighted MRI (C) showed a left cerebellar hemorrhage and surrounding edema. CT : computed tomography, MRI : magnetic resonance imaging. 

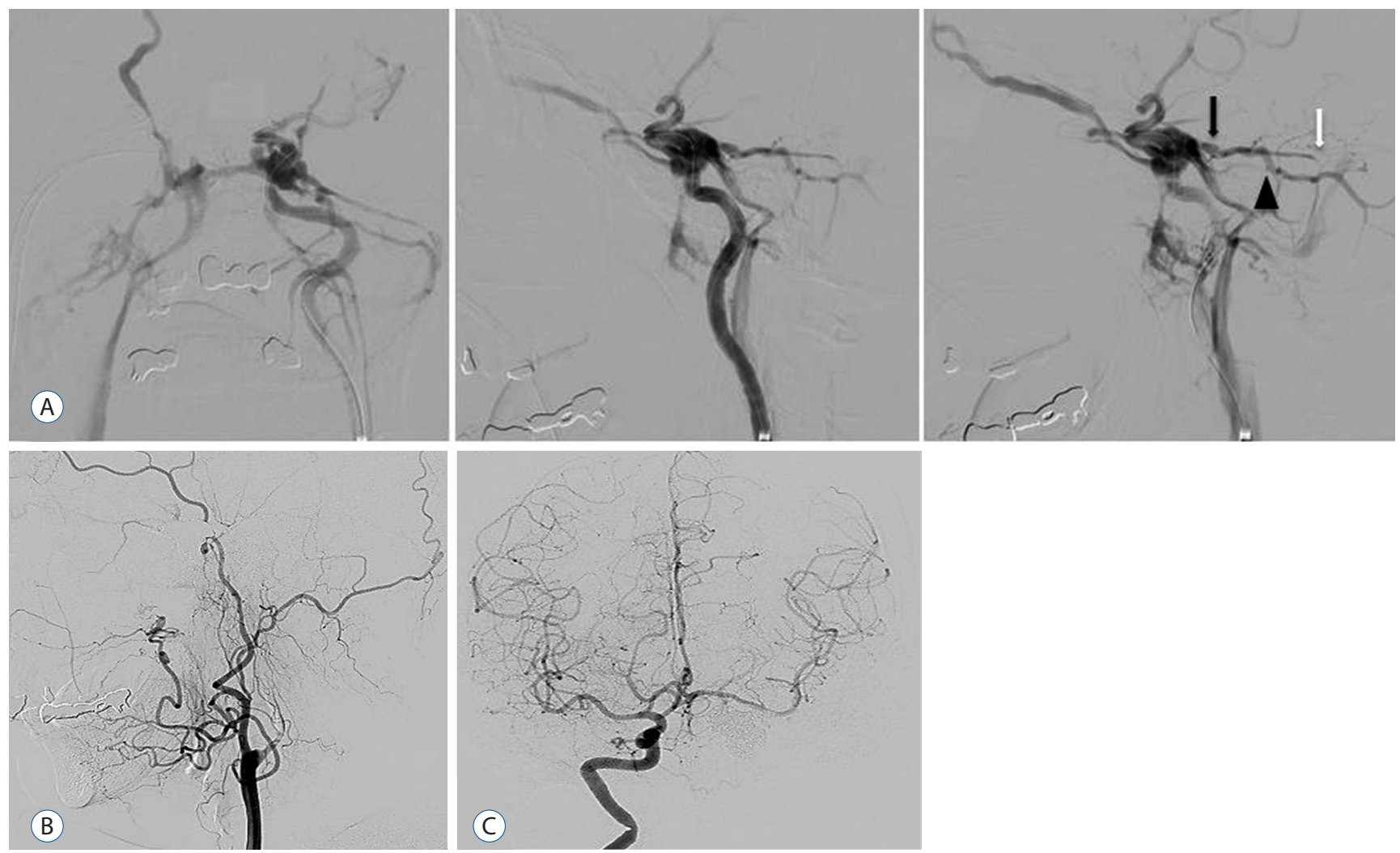

Fig. 2. The internal carotid artery angiogram (A) just before embolization, showing a high-flow direct carotid-cavernous fistula, engorgement of the proximal superior petrosal sinus (black arrow) and petrosal vein (black arrowhead), stenosis of the posterior segment of the superior petrosal sinus, and narrowing of the sigmoid sinus ostia (white arrow). B : Lateral view of the left carotid angiogram after embolization, showing disappearance of the fistula, cortical reflux, and occlusion of the internal carotid artery. C : Frontal view of the right internal carotid artery angiogram after embolization, showing left middle cerebral artery via anterior communicating artery and no visualization of the left internal carotid artery or the carotid-cavernous fistula.

drainage routes included the left petrosal vein via the left SPS, left inferior petrosal sinus (IPS), left superior ophthalmic vein (SOV), right SOV and right facial vein via the intercavernous sinus, right IPS, and right pterygoid plexus. There was stenosis of the posterior segment of the left SPS and narrowing of the left sigmoid sinus ostia. The left SOV, anterior segment of the left SPS, left cerebellar veins, and left petrosal vein were all engorged (Fig. 2A). After confirming tolerance by performing a balloon occlusion test of the left ICA, we performed left SOV, SPS and cavernous sinus (CS) occlusion by transarterial and transvenous embolization. We also performed ICA occlusion with fistulas because of difficulty of occlusion of fistulas alone due to large and complex fistulas. The fistula and abnormal drainage disappeared after embolization (Fig. 2B, C). The patient's level of consciousness, chemosis, conjunctival hyperemia, and orbital bruits improved, but the left-sided vision loss persisted.

\section{DISCUSSION}

Traumatic direct CCF is reported to occur in $0.2-0.3 \%$ of all cases of head and facial injury ${ }^{4}$. In the current case, the direct CCF was caused by surgery for maxillary cancer. Intracerebral hemorrhage from a direct CCF is thought to be secondary to venous hypertension and congestion caused by cortical venous reflux. In our patient, the surgery altered the venous drainage by sacrificing the left facial vein and pterygoid plexus. Given the stenosis of the posterior segment of the SPS, this could have resulted in increased pressure in the petrosal vein because there was stenosis of the posterior segment of the SPS. Intracerebral hemorrhage from a direct 
Table 1. Characteristics of intracerebral hemorrhage from a direct carotid-cavernous fistula

\begin{tabular}{|c|c|c|c|c|c|c|}
\hline Author/year & $\begin{array}{l}\text { Age/ } \\
\text { Sex }\end{array}$ & Location & Engorged vein & SPS hypoplasty & Treatment & Outcome \\
\hline Bartlow and Penn (1975) & $60 / M$ & Lt. Frontal & Subfrontal pial vein & - & TAE & $G R$ \\
\hline Vaghi et al. (1983) & $68 / M$ & Rt. Frontal & Frontal cortical vein, SOV & Unknown & Direct surgery & $\mathrm{MD}$ \\
\hline d'Angelo et al. $(1983)^{2)}$ & $54 / M$ & Lt. Frontal & Frontal cortical vein, SOV & Unknown & Balloon occlusion & MD \\
\hline Turner et al. (1983) & $41 / F$ & Rt. Temporal & SMCV & - & Balloon occlusion & $G R$ \\
\hline Teng et al. (1991) & $81 / F$ & $\begin{array}{l}\text { Midbrain, } \\
\text { Lt. hypothalamus }\end{array}$ & $\begin{array}{l}\text { APMV, vein in rostral } \\
\text { prepontine vein }\end{array}$ & Unknown & None & Death \\
\hline Teng et al. (1991) & $36 / M$ & $\begin{array}{l}\text { Temporo-parietal, } \\
\text { Midbrain }\end{array}$ & $\begin{array}{l}\text { Proximal SPS, } \\
\text { sphenoparietal sinus }\end{array}$ & + & Balloon occlusion & $G R$ \\
\hline Teng et al. (1991) & $41 / F$ & Pons & $\begin{array}{l}\text { Veins in pontine } \\
\text { parenchyma }\end{array}$ & + & TAE & $G R$ \\
\hline Murata et al. $(2003)^{7)}$ & $38 / \mathrm{M}$ & $\begin{array}{l}\text { Cerebello- } \\
\text { pontine angle }\end{array}$ & $\begin{array}{l}\text { Petrosal vein, Lateral ponto- } \\
\text { mesencephalic vein }\end{array}$ & Unknown & Unknown & Unknown \\
\hline Moon and Kang $(2005)^{6)}$ & $54 / \mathrm{M}$ & $\begin{array}{l}\text { Rt.Fronto- } \\
\text { parietal }\end{array}$ & SMCV, DCV & - & Balloon occlusion & $G R$ \\
\hline Hayashi et al. (2011) & $45 / F$ & Lt. frontal & SOV, SMCV & - & TVE, TAE & MD \\
\hline Present case & $63 / F$ & Lt. Cerebellum & $\begin{array}{l}\text { SOV, petrosal vein } \\
\text { Proximal SPS }\end{array}$ & + & TAE, TVE & MD \\
\hline
\end{tabular}

SOV : superior ophthalmic vein, APMV : anterior pontomesencephalic vein, SMCV : superficial middle cerebral vein, DCV : deep cerebral vein, TVE : transvenous embolization, TAE : transarterial embolization, SPS : superior petrosal sinus, GR : good recovery, MD : moderate disability

CCF is life-threatening, but rare. Lewis et al. ${ }^{5)}$ reported only one patient with intracerebral hemorrhage in a consecutive series of 100 patients with direct CCF. To our knowledge, only 10 cases of direct CCF with intracerebral hemorrhage have been reported, and cerebellar hemorrhage due to a direct CCF has not previously been reported (Table 1$)^{1-3,6,7,71-13)}$. In previously reported cases of supratentorial hemorrhage from a direct CCF, angiography showed engorgement of the superficial middle cerebral vein. Four of the 10 previously reported cases had infratentorial cerebral hemorrhage (midbrain, pons, and cerebellopontine angle), and two had SPS occlusion. These findings suggest that the SPS provides an important route for infratentorial venous drainage from the brainstem and cerebellum via the petrosal veins.

Shimada et al. ${ }^{10)}$ reported on variations of SPS drainage with normal hemodynamics. They found that more than $50 \%$ of SPSs had hypoplastic segments, and that the posterior segment of the SPS did not show up on angiography in $15.5 \%$ of cases. According to Padget ${ }^{8}$, the SPS develops primarily as a drainage route from the petrosal vein, receiving blood from the anterior cerebellar and brainstem venous drainage systems. This suggests that patients with a direct CCF and a hypoplastic posterior segment in the SPS have a higher risk of cortical venous reflux than patients with normal SPS drainage. Patients with a tentorial or transverse sigmoid sinus dural arteriovenous fistula have a higher risk of infratentorial cerebral hemorrhage, while patients with a fistula to the CS have a relatively low risk of hemorrhage because the CS has multiple drainage routes, like the pterygoid plexus, intercavernous sinus, and IPS. A direct CCF can drain through the petrosal, cerebellar, and sphenopetrosal veins via the anterior segment of the SPS if there is no stenosis of the posterior SPS stenosis, or through the uncal and bridging veins via the CS if there is hypoplasty of the SPS.

When considering endovascular treatment, the results of incomplete embolization should be considered. These include palliative transarterial embolization and/or residual drainages of a direct CCF with occlusion of the posterior route (pterygoid plexus and IPS) before the anterior route (ophthalmic veins), and occlusion of the anterior route before the CS. Such 
incomplete embolization changes the drainage routes and may result in secondary cortical reflux and increased venous pressure. The resulting engorgement of the cortical veins and drainage routes should be assessed preoperatively, and complete embolization should be achieved when possible.

\section{CONCLUSION}

We describe an extremely rare cerebellar hemorrhage due to a direct CCF has not previously been reported. Infratentorial cerebral hemorrhage is thought to be caused mainly by increased venous pressure and congestion via the SPS. It is important to consider that hypoplasty or occlusion of the SPS may increase the risk of infratentorial cerebral hemorrhage due to a direct CCF.

\section{References}

1. Bartlow B, Penn RD : Carotid-cavernous sinus fistula presenting as a posterior fossa mass. Case report. J Neurosurg 42 : 585-588, 1975

2. d'Angelo VA, Monte V, Scialfa G, Fiumara E, Scitti G : Intracerebral venous hemorrhage in "high-risk" carotid-cavernous fistula. Surg Neurol $30: 387-390,1983$

3. Hayashi K, Suyama K, Nagata I : Traumatic carotid cavernous fistula complicated with intracerebral hemorrhage: case report. Neurol Med Chir (Tokyo) 51 : 214-216, 2011

4. lida K, Uozumi T, Arita K, Nakahara T, Ohba S, Satoh H : Steal phenomenon in a traumatic carotid-cavernous fistula. J Trauma 39 : 10151017, 1995

5. Lewis Al, Tomsick TA, Tew JM Jr, Lawless MA : Long term results in direct carotid-cavernous fistula after treatment with detachable balloons.

J Neurosurg 84 : 400-404, 1996

6. Moon KY, Kang SD : Spontaneous intracerebral hematoma from transient occult carotid-cavernous fistula: a case report. J Korean Med Sci $20: 166-168,2005$

7. Murata H, Kubota T, Murai M, Kanno H, Fujii S, Yamamoto I : Brainstem congestion caused by direct carotid-cavernous fistula: case report. Neurol Med Chir (Tokyo) $43:$ 255-258, 2003

8. Padget $\mathrm{DH}$ : The development of the cranial venous system in man, from the viewpoint of comparative anatomy. Contrib Embryol 36 : 79-140, 1957

9. Sattler $\mathrm{CH}$ : Pulsierender exophthalmus. Handbuch der Gesamten Augenheilkunde. Berlin : Springer, 1920, pp1-268

10. Shimada R, Kiyosue $H$, Tanoue $S$, Mori $H, A b e ~ T$ : Superior petrosal sinus: hemodynamic features in normal and cavernous sinus dural arteriovenous fistulas. AJNR Am J Neuroradiol 34 : 609-615, 2013

11. Teng MM, Chang T, Pan DH, Chang CN, Huang Cl, Guo WY, et al. : Brainstem edema: an unusual complication of carotid cavernous fistula. AJNR Am J Neuroradiol 12 : 139-142, 1991

12. Turner DM, Vangilder JC, Mojtahedi S, Pierson EW : Spontaneous intracerebral hematoma in carotid-cavernous fistula. Report of three cases. J Neurosurg 59 : 680-686, 1983

13. Vaghi MA, Savoiardo M, Strada L : Unusual computerized tomography appearance of a carotid-cavernous fistula. Case report. J Neurosurg 58: 435-437, 1983 